\title{
EVALUACIÓN AMBIENTAL, CONSULTA INDÍGENA Y EL “DESPLAZAMIENTO” DE LOS DERECHOS DE LOS PUEBLOS INDÍGENAS
}

\author{
ENVIRONMENTAL ASSESSMENT, INDIGENOUS \\ CONSULTATION AND THE “DISPLACEMENT” OF \\ INDIGENOUS PEOPLES'RIGHTS
}

CRISTÓBAL CARMONA CALDERA*

\section{RESUMEN}

El artículo efectúa un análisis de la situación actual del derecho a consulta del Convenio $\mathrm{N}^{\circ} 169$ de la OIT en el Sistema de Evaluación de Impacto Ambiental y en la jurisprudencia ambiental. Al respecto, se postula que la consulta ha producido el efecto de desplazar las discusiones sobre los derechos sustantivos de los pueblos indígenas por debates de índole procedimental. Este "efecto de desplazamiento", se argumenta, se generaría por el uso de interpretaciones restrictivas en torno al criterio de procedencia y a la naturaleza de la consulta. El artículo examina los fundamentos jurídicos de dichas interpretaciones, concluyendo que estas descansan en lecturas erróneas de las fuentes pertinentes y, en consecuencia, que el "efecto de desplazamiento" identificado se puede explicar por la existencia de un sesgo infundado en la interpretación de la consulta.

*Investigador Adjunto y profesor de la cátedra de Derechos de los Pueblos Indígenas en la Facultad de Derecho de la Universidad Diego Portales, Santiago, Chile. Abogado y Magíster en Derechos Humanos y Democratización. Correo electrónico: cristobal.carmonac@mail.udp.cl. Código Orcid: https://orcid.org/0000-0002-6083-3640.

Agradezco los comentarios que Domingo Lovera, Dominique Hervé y Juan Jorge Faundes hicieran a versiones previas de este escrito, y a Pashka Nalegach y Teresita Chubretovic por los realizados a la versión final del texto. Asimismo, quisiera agradecer los comentarios de los pares revisores. Por supuesto, los errores que puedan existir en el texto son de mi exclusiva responsabilidad.

Artículo recibido para evaluación el 28 de julio de 2020, y aprobado para su publicación el 7 de diciembre de 2020 . 
Palabras clave: Derechos de los pueblos indígenas, Convenio $\mathrm{N}^{\circ} 169$, Consulta Indígena, Efecto de desplazamiento, Sistema de Evauación de Impacto Ambiental, Tribunales Ambientales.

\section{ABSTRACT}

The present work analyzes the current situation of the right to consultation of ILO Convention No. 169 in the Environmental Impact Assessment System and in the environmental jurisprudence. In this regard, it postulates that this right has displaced the discussions on the substantive rights of indigenous peoples for procedural debates. This "displacement effect", it is argued, is generated by the use of restrictive interpretations of the duty to consult. The article examines the legal foundations of these interpretations, concluding that they are based on erroneous readings of the relevant sources and, consequently, that the "displacement effect" can be explained by the existence of an unfounded bias in the interpretation of the duty to consult.

Keywords: Indigenous Peoples' rights, ILO Convention No169, Indigenous Consultation, Displacement effect, Environmental Impact Assessment System, Environmental Courts.

\section{INTRODUCCIÓN}

Al año 2008, una de las principales demandas de los pueblos indígenas en Chile decía relación con la protección de sus derechos frente al emplazamiento de proyectos de inversión en su territorio. ${ }^{1}$ La ratificación del Convenio No169 de la OIT (Convenio N¹69) ese mismo año aparecía como un hito importante para lograr dicho objetivo, especialmente a través de la aplicación del derecho a consulta. ${ }^{2}$ Este derecho, se pensaba, permitiría involucrar a las comunidades indígenas en el proceso de toma de decisión

\footnotetext{
${ }^{1}$ Egaña, Rodrigo, "Las Políticas Públicas en tiempos de crisis", Revista del CLAD Reforma y Democracia, 2009, N49, p. 2.

${ }^{2}$ Véase, por ejemplo, las expectativas de dirigentes Mapuche Williche, en: AguAS, Javier y NAHUELPAN, Héctor, "Los límites del reconocimiento indígena en Chile neoliberal. La implementación del Convenio 169 de la OIT desde la perspectiva de dirigentes Mapuche Williche", CUHSO, 2019, Vol. 29, №1, pp. 108-130, pp. 117-119.
} 
ambiental, lo que derivaría en una mayor y más representativa protección de sus derechos sustantivos. ${ }^{3}$

Han pasado ocho años desde que el Servicio de Evaluación Ambiental (SEA) decretara el inicio del primer Proceso de Consulta Indígena (PCI) en el Sistema de Evaluación de Impacto Ambiental (SEIA). Desde esa época se han abierto 56 procesos, ${ }^{4}$ muchos de los cuales han terminado con un acuerdo entre el Estado y los Grupos Humanos Pertenencientes a los Pueblos Indígenas (GHPPI) ${ }^{5}$ participantes. No obstante, y aun cuando este procedimiento supone una mejora en la participación indígena con respecto al escenario anterior, en distintos casos la consulta no ha podido cumplir con estas expectativas de protección de derechos, ${ }^{6}$ como lo evidencia la permanente judicialización en la materia. ${ }^{7}$ Esto, postulo, se debería en parte a que ciertos elementos del derecho a consulta han sido interpretados de forma tal que propician un desplazamiento de las discusiones sobre temas sustantivos -como los derechos afectados-, en favor de otros de índole procedimental o metodológico -como la forma de realización de la consulta o los requisitos que se deben cumplir para poder probar una determinada afectación-.

Esta idea del "efecto de desplazamiento" de la consulta, ha sido desarrollada por el jurista colombiano César Rodríguez. Para este autor, la consulta ha adquirido prominencia en el escenario jurídico latinoamericano por su capacidad de transformar "la sustancia en forma", de servir como "punto de contacto" entre actores que sostienen posiciones divergentes e, incluso, antagónicas. ${ }^{8}$ La consulta, dice RodríguEz, puede cumplir esta función gracias a sus características "procesales". En efecto,

\footnotetext{
${ }^{3}$ Rombouts, Sebastiaan, Having a Say. Indigenous Peoples, International Law and Free, Prior and Informed Consent, Wolf Legal Publishers, Nymegen, 2014, p. 79.

${ }^{4}$ Información obtenida de la página web del SEA: https://seia.sea.gob.cl/pci/proyectos_en_pci.php, consultada: 20 de noviembre de 2020.

${ }^{5}$ Esta es la denominación que utiliza el Reglamento del SEIA para referirse a los grupos indígenas que pueden ser afectados por un proyecto sometido a evaluación.

${ }^{6}$ Ver Aguas y Nahuelpan, cit. (n. 2), pp. 119-122; y Quilaleo, Fernando, "La implementación del Convenio 169 de la OIT en Chile: La paradoja de los derechos indígenas", Anuario de Derechos Humanos (Universidad de Chile), 2018, Nº14, pp. 148 y 149.

${ }^{7}$ Véase BARRíA, Jessica, "La consulta indígena en la institucionalidad ambiental de Chile: Consecuencias para la minería y las comunidades indígenas Collas de la Región de Atacama”, Investigaciones Geográficas, 2019, №57, 57, pp. 83 y ss.

${ }^{8}$ Rodríguez, César, Etnicidad.gov. Los recursos naturales, pueblos indigenas y el derecho a consulta previa en los campos sociales minados, Dejusticia, Bogotá, 2012, p. 57.
} 
serían las "formas" que están presentes en este derecho -los plazos, los cronogramas, etc.-, las que permitirían "la comunicación entre posiciones sustantivas inconmensurables". 9 Por lo mismo, es sobre estas cuestiones "procedimentales" que se centrarían -y en ocasiones se agotarían- las discusiones de un proceso de consulta, desplazándose con ello el debate sobre los temas de sustantivos. En este sentido, el "efecto de desplazamiento" de la consulta consiste en que "las controversias sobre los plazos, las certificaciones y el cronograma de reuniones tienden a soslayar los conflictos sobre la tierra, los recursos y la autodeterminación que están en el fondo de las consultas". ${ }^{10}$ Es este el fenómeno que, en general, creo que es posible identificar actualmente en el SEIA.

Ahora bien, en el caso del SEIA, por su propio diseño institucional las cuestiones sustantivas que se ven desplazadas son más acotadas que "la tierra, los recursos y la autodeterminación" a las que hace referencia Rodríguez. Como se sabe, una de las finalidades del SEIA tiene que ver con la identificación y valoración de los impactos ambientales que un proyecto pueda producir. ${ }^{11} \mathrm{Si}$ es una Declaración de Impacto Ambiental (DIA), su objetivo será determinar si se producen los "impactos significativos" del art. 11 de la Ley $\mathrm{N}^{\mathrm{o}} 19.300$ (art. 19 inc. $3^{\circ}$, Ley $\mathrm{N}^{\mathrm{o}} 19.300$ ). ${ }^{12}$ Si se trata de un Estudio de Impacto Ambiental (EIA), la evaluación apuntará a establecer si el proyecto se hace cargo adecuadamente de ellos (art. 16 inc. final, Ley $\mathrm{N}^{\mathrm{o}} 19.300$ ). Este marco y orientación del SEIA hace que las discusiones de fondo o sustantivas que se ven desplazadas no se refieran a temas como la vocación productiva de un territorio, el derecho a explotar ciertos recursos naturales o, inclusive, el emplazamiento de un proyecto. Cuestiones de este tipo son decididas de manera previa a la evaluación ambiental. Lo que se vería desplazado o relegado en el SEIA correspondería, en cambio, a las discusiones, en un marco culturalmente pertinente, sobre la generación, características y magnitud de los impactos -significativos y no significativosy la idoneidad de las medidas propuestas por el Titular para hacerse cargo de estos. ${ }^{13}$

\footnotetext{
${ }^{9}$ Rodríguez, cit. (n. 8), p. 61.

${ }^{10}$ Rodríguez, cit. (n. 8), p. 23.

${ }^{11}$ Bermúdez, Jorge, Fundamentos de Derecho Ambiental, Ediciones Universidad de Valparaíso, Santiago, 2015, 2da. edición, p. 276.

${ }^{12}$ En adelante, todas las referencias que se hagan en este artículo al "art. 11" se estarán refiriendo a la disposición del la Ley Nº19.300, 1994.

${ }^{13}$ Sobre el objeto de la consulta en el SEIA, ver Corte Suprema, 16 de junio de 2020, Rol № 28.195-
} 
Teniendo en cuenta esta precisión, son dos los objetivos del presente artículo. El primero, consiste en mostrar cómo las interpretaciones establecidas en la regulación administrativa, y reproducidas por la autoridad ${ }^{14}$ y la jurisprudencia ambiental, ${ }^{15}$ sobre el criterio de procedencia y la naturaleza de la consulta, desplazan y reemplazan las discusiones sobre los impactos y las medidas ambientales por debates de índole procesal y metodológico. Estas interpretaciones se refieren, particularmente, a sostener un criterio de procedencia que demanda certeza y magnitud en la afectación, y a entender a la consulta como una "obligación de medio". El segundo objetivo, es explicar de qué forma estas dos posturas hermenéuticas que propician el desplazamiento son jurídicamente erróneas. A partir de ello, la conclusión a la que se llega es que el "efecto de desplazamiento" de la consulta en el SEIA se debe a la prevalencia de un sesgo infundadamente restrictivo en la interpretación y aplicación de este derecho. Y, si esto es así, entonces dicho desplazamiento puede ser atenuado a partir de una lectura correcta del derecho a consulta en las referidas temáticas, lo que a su vez permitiría a a la consulta cumplir con su rol de protección de los derechos sustantivos de los pueblos indígenas.

Para sustentar esta idea, (II) comenzaré identificando ambas interpretaciones sobre la consulta y explicando cómo producen el "efecto de desplazamiento" durante la tramitación ambiental de los proyectos. A continuación, (III) revisaré la jurisprudencia del contencioso-administrativo ambiental en estas materias, examinando cómo esta ha seguido acríticamente dichas lecturas, reproduciendo así el referido desplazamiento. Luego, (IV) analizaré el sustento normativo de estas interpretaciones, mostrando cómo este se funda en lecturas jurídicamente parciales o erróneas de las fuentes pertinentes. Finalizaré (V) con una breve conclusión sobre el tema tratado.

\footnotetext{
2018, Considerando $7^{\circ}$.

${ }^{14}$ Para efectos de este artículo, "autoridad ambiental" considera tanto a las Direcciones Regionales y a la Dirección ejecutiva del Servicio de Evaluación Ambiental, como a las Comisiones de Evaluación de cada región.

${ }^{15}$ Para efectos de este artículo, "jurisprudencia ambiental" considera a los Tribunales Ambientales y a la Corte Suprema conociendo de casación las sentencias definitivas de estos tribunales.
} 
II. CONVIRTIENDO LA SUSTANCIA EN FORMA: LA CONSULTA EN EL SEIA

Recientemente Perter LARSEN ha notado cómo, en los países latinoamericanos que son parte del Convenio $\mathrm{N}^{\circ} 169$, “[m]ientras hace menos de una década los análisis apuntaban a la falta de consulta, el juego ha cambiado ahora a uno de ganar el proceso de determinación de la naturaleza y características de la consulta". ${ }^{16}$ Esta pugna hermenéutica por el significado de la consulta es importante. Dado que los significados de las normas dependen, además de los límites y las oportunidades creadas por los enunciados normativos, de las interpretaciones y estrategias de los actores que utilizan el derecho, ${ }^{17}$ entonces los efectos que produzcan dichas normas -entre ellos, el "efecto de desplazamiento"- serán consecuencia del "éxito que tengan las interpretaciones disímiles que compiten en una disputa específica". ${ }^{18}$

En este orden de ideas, no resulta extraño que la generación del "desplazamiento" en el SEIA derive de la afirmación de dos interpretaciones concretas sobre las características y la naturaleza de la consulta. Una de ellas, (1) lee el criterio de procedencia de la consulta como requiriendo certeza y magnitud del impacto. La otra, (2) entiende a la consulta como una "obligación de medio". En los apartados que siguen identificaré cada una de estas posturas, explicando a su vez de qué manera producen el mentado "efecto de desplazamiento".

\section{Criterio de procedencia: certeza y magnitud de la afectación}

Es conocido que el actual Reglamento del SEIA (RSEIA) (D.S. Nº40, 2012), adoptó un criterio de procedencia de la consulta que homologa la "susceptibilidad de afectación directa" requerida por el art. 6 N¹(a) del Convenio $\mathrm{N}^{\mathrm{o}} 169$, con los "impactos significativos" del art. 11, que son los que hacen obligatoria la presentación de un EIA. En efecto, de acuerdo con lo dispuesto en el art. 85 y los incisos finales de los arts. 5, 6 y 9 de

\footnotetext{
${ }^{16}$ LARsen, Peter, "Contextualising ratification and implementation: a critical appraisal of ILO Convention 169 from a social justice perspective", The International Journal of Human Rights, 2020, Vol. 24, No2-3, p. 99. Traducción del autor.

${ }^{17}$ Rodríguez, cit. (n. 8), p. 52.

${ }^{18}$ RodríGuez, cit. (n. 8), p. 53.
} 
este cuerpo normativo, directa o indirectamente cualquiera de los impactos significativos establecidos en los 6 literales del art. 11 puede "gatillar" un proceso de consulta. ${ }^{19}$ Este criterio fue complementado posteriormente con la dictación, por parte de la Dirección Ejecutiva del SEA (DE del SEA), del Instructivo sobre Consulta Indígena en el SEIA (Instructivo), ${ }^{20}$ en donde, entre otras cosas, se establece una interpretación restrictiva de la circunstancia establecida en el art. 11 letra d). De esta forma, la regulación ambiental requiere para hacer procedente la consulta la existencia no solo de "alteraciones" o "efectos adversos", sino que además estos sean, en la mayoría de los casos, "significativos".

En términos de la evaluación ambiental, la principal consecuencia de esta regulación es que se circunscribe la consulta a los proyectos evaluados por un EIA, los que corresponden solo al 4,6\% de los proyectos ingresados al SEIA. ${ }^{21}$ Para los pueblos indígenas, especialmente para todos aquellos GHPPI respecto de los cuales no se reconocen impactos significativos, esto significa reducir y complejizar su participación en la determinación de impactos y, consecuentemente, desplazar los debates sustantivos por cuestiones procedimentales. Específicamente, producto de este estricto criterio de procedencia los GHPPI deberán sortear dos tipos de barreras institucionales para poder acceder a una discusión de fondo. Primero, deberán actuar dentro de los plazos y márgenes procedimentales establecidos por la evaluación ambiental para poder formular su punto de vista de una manera que sea procesable por el sistema. Segundo, para refutar el juicio del titular y de la autoridad ambiental sobre la inexistencia de impactos, el contenido de las observaciones efectuadas deberá dar cuenta de una afectación objetiva y de cierta magnitud. ${ }^{22}$ Por estas dos razones, las organizaciones indígenas deberán involucrarse en discusiones procedimentales y metodológicas que

\footnotetext{
${ }^{19}$ Ver, en general, Durán, Álvaro, "La Susceptibilidad de Afectación Directa a los Pueblos Indígenas como requisito de procedencia de la consulta a los pueblos indígenas en el Sistema de Evaluación de Impacto Ambiental", Revista de Derecho Universidad Finis Terrae, 2017, Año V, No2, pp. 154-160.

${ }^{20}$ DE del SEA, Of. Ord. $\mathrm{N}^{\circ} 16111$ del 24 de agosto de 2016, que establece el "Instructivo sobre el Proceso de Consulta a Pueblos Indígenas en conformidad con el Convenio $\mathrm{N}^{\circ} 169$ de la OIT en el SEIA".

${ }^{21}$ FuENTES, Claudio, "Evaluación de impacto ambiental en Chile: Análisis de tendencias 1992-2017", Documento de Trabajo ICSO - N ${ }^{\circ} 59$ / 2019, 2019, p. 6, https://labconstitucional.udp.cl/documentos/ evaluacion-de-impacto-ambiental-en-chile-analisis-de-tendencias-1992-2017/, consultada: 12 de julio de 2020.

${ }^{22}$ Sobre la facultad del SEA para determinar la existencia o inexistencia de estos impactos, véase Contraloría General de la República, 24 de abril de 2015, Dictamen № 32.996.
} 
desplazan los debates sobre las posibles afectaciones y las formas de hacerse cargo de ellas.

Para ilustrar el punto, puede ser útil pensar en el caso hipotético de un GHPPI que quiera alegar la existencia de un impacto significativo a su respecto durante la evaluación ambiental de un proyecto. A primera vista, dos son las instancias que el diseño institucional ofrece para ello: las "reuniones con GHPPI" del art. 86 del RSEIA y el proceso de PAC. Aunque las reuniones del art. 86 son en general una herramienta importante dentro de la evaluación, y en ocasiones sí han permitido al SEA recabar información para justificar la apertura de un PCI, ${ }^{23}$ difícilmente pueden ser una instancia idónea para que los GHPPI planteen adecuadamente sus alegaciones sobre la afectación del proyecto. Ello se debe a que se desarrollan en una etapa de la evaluación en donde es poco probable que el grupo sea capaz de comprender los reales alcances del proyecto -dentro de los 30 primeros días en los EIA y los 20 en las DIA (art. 86, RSEIA)-. Por lo anterior, la vía principal para alegar la existencia de impactos significativos será ingresando "observaciones ciudadanas" durante un proceso de Participación Ciudadana (PAC).

En las DIA, la PAC no es obligatoria para el servicio, sino que debe ser solicitada y será facultativo del respectivo Director Regional del SEA el acoger o rechazar dicha solicitud (art. 94, inc. $3^{\circ}$, RSEIA). Al efectuar esta petición de PAC, las organizaciones indígenas no solo deberán estar preocupadas de cumplir con el plazo de 10 días desde la presentación del proyecto en el Diario Oficial (art. 94, inc. $3^{\circ}$, RSEIA), sino también de justificar que el proyecto provoca "cargas ambientales" (art. 94, incisos $6^{\circ} \mathrm{y}$ $7^{\circ}$, RSEIA). Esta última cuestión genera un nivel de complejidad importante, toda vez que implica entrar a una disputa interpretativa acerca de diversos elementos relacionados con este concepto. Por ejemplo, respecto a si el listado de proyectos establecido en el inc. $7^{\circ}$ del art. 94 del RSEIA es taxativo o no, ${ }^{24} \mathrm{o}$ la amplitud del concepto de "beneficios sociales". ${ }^{25}$ Por lo demás, una respuesta negativa a la solicitud de PAC obligará a la organización a

\footnotetext{
${ }^{23}$ Véase, por ejemplo, el caso de la C.I. Colla de Diego de Almagro en el proyecto "Rajo Inca". SEA Atacama, Res. Ex. No5 de 10 de enero de 2019, < https://seia.sea.gob.cl/archivos/2019/01/10/ INICIO_PC_RAJO_INCA.PDF>, consultada: 15 de julio de 2020.

${ }^{24}$ Véase Corte Suprema, 15 de mayo de 2019, Rol No 197-2019, Considerando $16^{\circ}$.

${ }^{25}$ En distintos fallos la Corte Suprema ha considerado un criterio amplio de "beneficios sociales" mientras que el SEA ha afirmado una concepción restringida del mismo. Véase, por ejemplo, Corte Suprema, 16 de marzo de 2017, Rol No 55.203-2016.
} 
analizar y ejecutar estrategias de litigación contra esta resolución, lo que supone enfrascarse en una serie de discusiones procesales adicionales en torno a la eficiencia y eficacia de los recursos administrativos y judiciales disponibles. ${ }^{26}$

Una vez iniciada la PAC, la organización no solo deberá procurar que su observación cumpla con los requisitos formales ${ }^{27}$ y sea "pertinente"28 para ser admitida. Dado que en función del "principio de congruencia" el GHPPI solo podrá hacer valer en una eventual reclamación judicial cuestiones previamente levantadas en la reclamación administrativa y en la observación ciudadana, el grupo tendrá además que intentar ser lo más exhaustivo posible en el rango de temáticas observadas. De lo contrario, se arriesga que se desestimen sus alegaciones en sede judicial. ${ }^{29} \mathrm{La}$ formulación de la observación generalmente marcará el fin de la participación efectiva del GHPPI durante la evaluación ambiental. Empero, en el caso de un EIA, la organización indígena podría solicitar directamente la apertura de un PCI -o el ingreso a una consulta ya abierta- con posterioridad al cierre de la PAC. ${ }^{30}$

Tanto en las observaciones ciudadanas como en estas solicitudes de apertura/ingreso a un PCI, el GHPPI deberá cumplir con el estándar de certeza y magnitud exigido por la regulación ambiental para refutar el juicio del titular. Es cierto que normativamente es obligación de este último sujeto el justificar en la DIA y en el EIA la inexistencia de los efectos, características y circunstancias del art. 11 (respectivamente, arts. 19(b)6 y 18(g), RSEIA)

\footnotetext{
${ }^{26}$ Sobre las incertidumbres en torno al recurso de protección, véase CARRASCO, Edesio, "De Trillium a Central Los Cóndores: continuidad y cambio del recurso de protección ambiental en veinte años de jurisprudencia", Justicia Ambiental, 2017, №9, pp. 275-298. Sobre las complejidades procedimentales que enfrentan los pueblos indígenas ante los Tribunales Ambientales, véase HERvÉ, Dominique y BASCUR, Débora, "La Protección de los Derechos de las Comunidades Indígenas en el Sistema de Evaluación de Impacto Ambiental por Parte de los Tribunales Ambientales: ¿Avance y/o Retroceso?”, Justicia Ambiental, 2019, № 11, pp. 197-232.

${ }^{27}$ DE del SEA, Of. Ord. $N^{\circ} 100142$ del 15 de noviembre de 2010, que establece el "Instructivo de admisibilidad de las Observaciones Ciudadanas en el marco del SEIA".

${ }^{28}$ DE del SEA, Of. Ord. No 130528 del 1 de abril de 2013, que establece el "Instructivo sobre la consideración de las Observaciones Ciudadanas en el marco del SEIA".

${ }^{29}$ Ver, por ejemplo: Tercer Tribunal Ambiental, 27 de noviembre de 2019, Rol No R-9-2019, Considerandos $15^{\circ}$ a $20^{\circ}$.

${ }^{30}$ Ver, por ejemplo, el caso de la Comunidad Indígena Quechua de Ollagüe en el proyecto “Ampliación Proyecto Central Geotérmica Cerro Pabellón". SEA Antofagasta, Res. Ex. №133 de 19 de junio de 2019, https://seia.sea.gob.cl/archivos/2019/06/11/20190607172310813.pdf, consultada: 11 de abril de 2020 .
} 
y de hacerse cargo de las observaciones ciudadanas. De igual forma, si el GHPPI solicita la apertura/ingreso al PCI, la autoridad ambiental deberá dar respuesta fundada a su requerimiento. Por ende, aun una observación/ solicitud poco precisa por parte del GHPPI será suficiente para activar el deber del titular y de la autoridad ambiental de justificar la inexistencia del impacto alegado. No obstante, dado que el criterio de procedencia de la consulta en el SEIA requiere impactos significativos, si el GHPPI pretende tener éxito en su reclamación deberá articular su observación/solicitud de una manera que cumpla con los mentados estándares. Como se observa en el caso de las solicitudes de apertura/ingreso al PCI, aunque en ocasiones pueda existir una respuesta positiva del SEA, ${ }^{31}$ en muchas otras este servicio denegará la solicitud, amparándose en el alto umbral de certeza y magnitud en la afectación requerido por el RSEIA y el Instructivo. ${ }^{32}$ Este tipo de rechazos en base al estricto criterio de procedencia consagrado en la regulación ambiental, típicamente generará dos clases de respuestas por parte de los grupos indígenas. En lo inmediato, el GHPPI intentará impugnar la decisión del SEA de denegar la apertura/ingreso de un PCI a partir de un recurso de protección, ${ }^{33}$ de un recurso reposición ${ }^{34} \mathrm{o}$, incluso, de una denuncia a Contraloría. ${ }^{35}$ En términos más amplios, teniendo en cuenta las dificultades que puede suponer el generar evidencia científica que dé cuenta de la afectación, el comportamiento del GHPPI posiblemente se enfocará en un análisis crítico de la metodología utilizada por el titular para

${ }^{31}$ Un ejemplo de ello lo constituye el caso de la Asociación Indígena Aymara Ganadera y Cultural Quebrada Yabricollita y Caya en el proyecto “Actualización Proyecto Minero Quebrada Blanca". SEA Tarapacá, Res. Ex. No 89 de 18 de diciembre de 2015, https://seia.sea.gob.cl/archivos/2015/12/21/ RE_890001.pdf, consultada:12 de abril de 2020.

${ }^{32}$ Ver, por ejemplo, la respuesta del SEA en el proyecto "Ramal de distribución para abastecimiento de gas natural al observatorio ALMA". SEA Antofagasta, Res. Ex. №227 de 23 de junio de 2017, https://seia.sea.gob.cl/archivos/2017/06/28/RCA_0227_Apertura_PAC_EIA_ALMA.pdf, consultada: 5 de abril de 2020 .

${ }^{33}$ Ver, por ejemplo, el recurso de protección interpuesto por los Comuneros proindiviso del predio denominado "Collacagua Hijuela Número Uno" contra la resolución de inicio del PCI en el proyecto "Continuidad Operacional Cerro Colorado", en Corte de Apelaciones de Iquique, 18 de febrero de 2014, Rol No 27-2014.

${ }^{34}$ Ver, por ejemplo, el recurso de reposición con jerárquico en subsidio en contra de la resolución que rechazó su inclusión en el PCI, interpuesto por la AGI de Copaquire en el proyecto "Actualización Proyecto Minero Quebrada Blanca”. SEA Tarapacá, Res. Ex. Nº2 de 23 de julio de 2016, https://seia. sea.gob.cl/archivos/2016/08/04/RE_62_290716.pdf, consultada: 12 de abril de 2020 .

${ }^{35}$ Este fue el caso de la Asociación Indígena Aymara de Cancosa en el en el proyecto "Continuidad Operacional Cerro Colorado". Ver Contraloría General de la República, 12 de noviembre de 2014, Dictamen Nº88.248 y Contraloría General de la República, 24 de abril de 2015, Dictamen №32.996. 
descartar la producción de impactos significativos. Ambas estrategias no hacen sino profundizar la inmersión del grupo en debates procedimentales. La impugnación de la resolución del SEA significará seguir adentrándose en controversias sobre los plazos, el tipo de acción y futuras apelaciones. El análisis de la prueba entregada por el titular, en tanto, implicará detenerse en discusiones sobre reglas metodológicas de la investigación y producción de conocimiento científico.

En síntesis, en base al criterio de procedencia dispuesto en el RSEIA, los GHPPI que intenten refutar la apreciación sobre la inexistencia de impactos significativos deberán lidiar con una serie de debates procesales y metodológicos, los que de esta forma desplazan las controversias que existen en el fondo de la consulta sobre los derechos posiblemente afectados y las medidas para hacerse cargo de dicha afectación.

\section{Obligación de medio}

La segunda interpretación sobre la consulta que genera el "efecto de desplazamiento", es aquella que comprende a este derecho como una "obligación de medio", en oposición a lo que sería una "obligación de resultado". ${ }^{36}$ La comprensión como "obligación de medio" significa que el Estado se obliga a consultar de buena fe a través de procedimientos apropiados con el fin de llegar a un acuerdo o lograr el consentimiento, pero de una forma según la cual el no alcanzar el consentimiento no implica afectar el derecho a consulta (art. 85, inc. $2^{\circ}$, RSEIA). Al contrario, como prescribe el Reglamento General de Consulta (RGC), ${ }^{37}$ "se tendrá por cumplido el deber de consulta, aun cuando no resulte posible alcanzar dicho objetivo" (art. 3, RGC). Eso sí, siempre y cuando el Estado haga todos los esfuerzos razonables para intentar obtenerlo. ${ }^{38}$ Es decir, la consulta se cumple respetando las garantías procesales que den muestra de la voluntad estatal de llegar a un acuerdo, con independencia de si se obtiene o no el consentimiento del GHPPI.

Ahora bien, no es que el Estado no tenga que llevar a cabo estas obligaciones procesales. Al contrario, debe hacerlo. No obstante, el

\footnotetext{
${ }^{36}$ Por ejemplo, Donoso, Sebastián, "Empresas y comunidades indígenas: el nuevo escenario que plantea el Convenio 169 de la OIT”, Temas de la agenda Pública, 2014, Vol. 9, N73, p. 13.

${ }^{37}$ D.S. N ${ }^{\circ} 66$ de 2013.

${ }^{38}$ Ver Corte de Apelaciones de Santiago, 20 de octubre de 2014, rol 19.839-2014, considerando $9^{\circ}$.
} 
considerar a la consulta como una "obligación de medio" produce el desplazamiento de las cuestiones sustantivas porque el "test de cumpliento" del derecho a consulta ante la ausencia de consentimiento se detiene en ese punto, es decir, en la revisión formal de las etapas del procedimiento. No se extiende a analizar cuál es el resultado que tendrá la implementación de una medida en relación con los derechos sustantivos de los pueblos indígenas. El PCI sería, en esta concepción, una especie de manifestación de la "justicia procesal pura", ${ }^{39}$ al funcionar como un mecanismo "en el cual se le atribuye legitimidad a un resultado, solo debido a las características del procedimiento". ${ }^{40}$

En la práctica, esta noción de que la consulta constituye una "obligación de medio" se ha traducido en que, para verificar el cumplimiento de este derecho, se debe chequear si se realizaron las ritualidades procesales que permitan inferir el desempeño de buena fe del SEA y su voluntad de lograr un acuerdo. ${ }^{41}$ No existiría el deber de explicar, por ejemplo, por qué la medida propuesta por el titular podía considerarse idónea para hacerse cargo del impacto, a pesar del rechazo del GHPPI. De esta forma, lo que comúnmente está en el fondo de un PCI en el SEIA -i.e., la discusión sobre la idoneidad de las medidas para hacerse cargo del impacto-, queda relegado en favor de un análisis de la corrección del procedimiento.

El término del PCI llevado adelante entre el SEA y la Asociación Indígena Koñintu Lafken Mapu en el proyecto "Terminal GNL PencoLirquén”, constituye un buen ejemplo de cómo opera la autoridad ambiental en este tema. Después de más de tres años de un proceso de consulta que involucró, entre otras cosas, un término anticipado del PCI y una sentencia de la Corte Suprema invalidando dicha decisión, ${ }^{42}$ en julio del 2018 la Asociación y el SEA firman un Protocolo de Acuerdo Final. En este, se declara que no se llegó a acuerdo en torno a las medidas consultadas. En términos concretos, la Asociación rechazó cada una de las 8 medidas

\footnotetext{
${ }^{39}$ Rawls, John, Teoría de la Justicia, FCE, México, 1990, p. 90.

${ }^{40}$ Millaleo, Salvador, “¿Gobernar Consultado? Análisis comparativo respecto a los problemas en relación a las bases y objetos de la consulta indígena (Convenio 169) de los reglamentos aprobados en Chile", en ¿Chile indigena? Desafios y oportunidades para un nuevo trato, Fundación Chile, Santiago, 2014, pp. 56 y 57.

${ }^{41}$ Esto explica que el Instructivo de consulta ponga especial énfasis en la necesidad de "dejar registro de todas las comunicaciones telefónicas, campañas de terreno, cartas, correos electrónicos, etc., en donde conste la voluntad de facilitar la construcción de confianzas, generación de alternativas y acuerdos con los GHPPI”. DE del SEA, Of. Ord. N¹6111 del 24 de agosto de 2016, pp. 10 y 11.

${ }^{42}$ Corte Suprema, 30 de enero de 2017, Rol No 65.349-2016, Considerando $9^{\circ}$.
} 
ambientales propuestas por el titular del proyecto para hacerse cargo de los tres impactos significativos identificados. Para ello, la Asociación acompañó una serie de fundamentos de carácter antropológico explicando, medida por medida, las razones de por qué estas no eran adecuadas para hacerse cargo de los impactos. En lo medular, sus argumentos giraban en torno al hecho que las medidas fallaban en comprender la significación cultural que dentro de la cosmovisión mapuche tenían los diversos recursos y sitios afectados. ${ }^{43}$

No obstante, la autoridad ambiental en ningún momento se hace cargo de dichos argumentos. En efecto, ni en el Protocolo de Acuerdo Final, ni el Informe Final del Proceso de Consulta, ni en la resolución de término del PCI, ni en la RCA que calificó favorablemente el proyecto puede encontrarse mención alguna del SEA o la Comisión de Evaluación (COEVA) al respecto. En la RCA, por ejemplo, al momento de abordar el PCI, la COEVA efectúa un repaso de los distintos actos, gestiones y reuniones que se hicieron en cada etapa del proceso de consulta, para luego consignar que la Asociación manifestó "su desacuerdo con cada una de las (8) medidas ambientales propuestas por el titular". ${ }^{44}$ A pesar de ello, señala, el PCI "cumplió con el estándar del Convenio No169 de la OIT, se realizó a través de sus instituciones representativas, de buena fe y con la intención de lograr un acuerdo". ${ }^{45}$ Esto, a la vez que declara en otra parte de la resolución que las medidas existentes son suficientes para hacerse cargo de los impactos del proyecto ${ }^{46}$ Con mayor o menor detalle, esta es la forma en que las distintas direcciones regionales del SEA y comisiones de evaluación abordan el cumplimiento de los procesos de consulta. ${ }^{47}$

Como puede observarse, para el SEA y la COEVA el derecho a

\footnotetext{
${ }^{43}$ Ver Protocolo de Acuerdo Final Proceso de Consulta a Pueblos Indígenas con la Asociación Indígena Koñintú Lafken Mapu, por el Estudio de Impacto Ambiental del proyecto "Terminal GNL Penco-Lirquén", 2019, https://seia.sea.gob.cl/archivos/2018/08/02/PAF_PCPI_GNL_Penco_Lirquen_ Konintu_Lafken_Mapu.pdf, consultada: 12 de abril de 2020.

${ }^{44}$ Comisión de Evaluación Región del Biobío, Res. Ex. No219 de 30 de octubre de 2019, p. 172, https:// seia.sea.gob.cl/archivos/2019/11/29/145_RE_219_GNL_PENCO_LIRQUEN.pdf, consultada: 15 de abril de 2020 .

${ }^{45}$ Comisión de Evaluación Región del Biobío, Res. Ex. N²19 de 30 de octubre de 2019, p. 172.

${ }^{46}$ Comisión de Evaluación Región del Biobío, Res. Ex. №219 de 30 de octubre de 2019, pp. 25 y 26; y pp. 44-50.

${ }^{47}$ Para un análisis en este sentido de un proyecto evaluado bajo el reglamento anterior del SEIA, véase CARMona, Cristóbal, “¿La identidad cultural como límite de la Consulta Indígena en el SEIA? Notas para una subversión de la comprensión "procedimental" de la consulta", en: FAUNDES, J.J. y RAMÍREZ, S. (Eds.), Derecho fundamental a la identidad cultural: Abordajes plurales desde América Latina, RIL editores/Universidad Autónoma de Chile, Santiago, 2020, pp. 343-359.
} 
consulta supone un derecho que genera solo obligaciones procesales por parte del Estado: su cumplimiento se verifica acá a partir de un chequeo de las acciones realizadas, pero sin prestar mayor atención a si, a la luz de las observaciones presentadas por el GHPPI consultado, efectivamente las medidas son adecuadas para hacerse cargo de los impactos. De hecho, este estándar es incluso inferior a aquel de la PAC, en donde al menos existe la obligación de la autoridad de "hacerse cargo de ellas, pronunciándose fundadamente en su resolución" (art. 83, inc. $4^{\circ}$ RSEIA). ${ }^{48}$ Con una lógica como esta, es evidente que para los GHPPI que no llegaron a acuerdo en el PCI, las cuestiones sustantivas terminan siendo reemplazadas y desplazadas por dicusiones de índole procedimental.

\section{LA JURISPRUDENCIA DEL CONTENCIOSO-ADMINISTRATIVO AMBIENTAL Y LA REPRODUCCIÓN DEL DESPLAZAMIENTO}

Habiendo concluido un proceso de evaluación en donde no se identificó la generación de impactos significativos respecto de uno o más GHPPI y/o no se llegó a acuerdo en un PCI con una de las organizaciones afectadas, está la opción para estos grupos de impugnar judicialmente la RCA a través del procedimiento contencioso-administrativo. Para ello, una vez agotada la vía administrativa correspondiente, los GHPPI podrán interponer ante los Tribunales Ambientales los recursos de reclamación establecidos en los art. $17 \mathrm{~N}^{\circ} 6$ y $17 \mathrm{~N}^{\circ} 8$ de la Ley $\mathrm{N}^{\circ} 20.600$ de 2012 , dependiendo de cuál fue la participación que tuvieron durante la evaluación. ${ }^{49} \mathrm{Si}$ el resultado es adverso, se podrá recurrir de casación ante la Corte Suprema (art. 26, incisos $3^{\circ}$ y $^{\circ}$, Ley $\mathrm{N}^{\circ} 20.600$ ).

Enfrentados a estas reclamaciones, los tribunales del contencioso-

\footnotetext{
${ }^{48}$ Agradezco a Matías Guiloff por hacerme ver este punto. Con todo, se debe hacer mención que, en algunos proyectos, si bien la autoridad ambiental no se hace cargo de los argumentos formulados por el grupo consultado para rechazar las medidas propuestas, sí existe un pronunciamiento y análisis técnico de los "impactos y preocupaciones" expresadas por el GHPPI durante la consulta. Ver, por ejemplo, el caso de la Comunidad Indígena Huayún Mapu en Informe Final Proceso de Consulta a Pueblos Indígenas Estudio de Impacto Ambiental Proyecto Parque Eólico Calbuco, 2019, https://seia.sea.gob. cl/archivos/2019/10/04/INFORME_FINAL_PCPI_EIA_Parque_Eolico_Calbuco.pdf, consultada: 23 de noviembre de 2020.

${ }^{49}$ Cabe consignar que, en la legislación ambiental, no existe una acción específica para que aquellos pueblos que han participado de un PCI puedan reclamar por temas discutidos en este proceso. Véase, Hervé y BASCur, cit. (n. 26), pp. 204 y 205.
} 
administrativo ambiental han optado por reproducir las dos interpretaciones revisadas en el apartado anterior. Así, han mantenido acríticamente (1) un criterio de procedencia de la consulta que requiere certeza y magnitud en la afectación al fijar como estándar la generación de impactos significativos;y(2) han apuntado a una comprensión de la consulta como "obligación de medio". De esta forma, se verá, las decisiones de estos tribunales han contribuido a reproducir el "efecto de desplazamiento" de la consulta, reemplazando los debates sustantivos por discusiones de orden procedimental.

\section{Consulta Indígena y la necesidad de una "afectación directa y significativa"}

Se ha visto ya que la regulación ambiental ha definido como criterio de procedencia de la consulta en el SEIA, la generación por parte del proyecto de los efectos, características o circunstancias establecidos en el art. 11; es decir, los llamados "impactos significativos" (art. 2(e) inc. $2^{\circ}$, RSEIA). Esto ha traído como consecuencia la inmersión de los GHPPI en debates de orden procedimental y metodológico para intentar hacer presentes impactos no reconocidos por el titular y la autoridad. A continuación, mostraré cómo los tribunales del contencioso-ambiental han mantenido este criterio procedencia, profundizado con ello el desplazamiento de los debates sustantivos.

El primer ejemplo de esta postura hermenéutica lo constituye el caso "Paguanta II". En esta causa, el Segundo Tribunal Ambiental (STA) y la Corte Suprema rechazaron los recursos de diversas organizaciones indígenas relativos a que el PCI efectuado no había considerado a todas las comunidades afectadas. ${ }^{50}$ Las razones esgrimidas por estos tribunales para denegar las reclamaciones se centraron en la ausencia de "datos objetivos" de "afectación directa" 51 por parte de las organizaciones reclamantes, que permitieran desvirtuar el juicio de la autoridad ambiental.

De forma interesante, esta interpretación ha sido reforzada incluso en casos en donde los tribunales terminan invalidando la RCA impugnada, como "Central Mediterráneo" y "Central Doña Alicia”. Recuérdese que, en ambos casos, la COEVA y el Comité de Ministros habían determinado

\footnotetext{
${ }^{50}$ Segundo Tribunal Ambiental, 1 de diciembre de 2015, Rol No R-54-2014 y Corte Suprema, 19 de mayo de 2016, Rol No 817-2016.

${ }^{51}$ Corte Suprema, 19 de mayo de 2016, Rol No 817-2016, Considerando $15^{\circ}$.
} 
la inexistencia de impactos significativos respecto de las comunidades indígenas del área de influencia, amparándose principalmente en los informes antropológicos acompañados por el titular. Ante ello, en el Tercer Tribunal Ambiental (TTA) falló que dichas conclusiones eran infundadas, por las deficiencias metodológicas que presentaban dichos informes. ${ }^{52}$ Estos defectos metodológicos hacían que no fuera factible concluir respecto de la ausencia de impactos significativos. ${ }^{53}$ Coherentemente, el TTA invalidó las resoluciones respectivas, en fallos que fueron confirmados por la Corte Suprema. ${ }^{54}$

Ahora bien, a pesar de haber anulado las RCA y haber rechazado los argumentos de la autoridad relativos a que las comunidades debían explicitar durante la evaluación cómo les afectaría el proyecto, ${ }^{55}$ lo que es importante subrayar acá es que el TTA continúa requiriendo evidencia de impactos significativos para estimar procedente la obligación de consulta. Al respecto, se debe notar que tanto en "Central Mediterráneo" como en "Central Doña Alicia" los reclamantes habían afirmado que el proyecto sí generaba los efectos del art. 11 y que, por tanto, era procedente un PCI. En "Central Mediterráneo", el TTA responde argumentado que las deficiencias metodológicas de los informes hacen que estos no sean confiables para concluir sobre la procedencia o improcedencia de la consulta ${ }^{56}$ y que "a esa evaluación no se aparejó evidencia alternativa a la evaluación ambiental". ${ }^{57}$ En "Central Doña Alicia", no solo se descarta la alegación relativa a la existencia de impactos significativos en base a que el recurrente no

\footnotetext{
${ }^{52}$ En "Doña Alicia", además, se tuvo en consideración la falta de fundamentación del oficio de CONADI que sostenía la ausencia de afectación. Ver Tercer Tribunal Ambiental, 28 de diciembre de 2016, Rol $\mathrm{N}^{\mathrm{o}} \mathrm{R}-38-2016$, Considerando $32^{\circ}$.

${ }^{53}$ Ver respectivamente Tercer Tribunal Ambiental, 17 de noviembre de 2016, Rol No R-30-2016, cons. $50^{\circ}$; y Tercer Tribunal Ambiental, 28 de diciembre de 2016, Rol No R-38-2016, Considerandos $34^{\circ} \mathrm{y}$ $35^{\circ}$.

${ }^{54}$ Respectivamente, Corte Suprema, 29 de diciembre de 2017, Rol No 100.805-2016 y Corte Suprema, 28 de junio de 2018, Rol No 3.971-2017.

${ }^{55}$ Ver Tercer Tribunal Ambiental, 17 de noviembre de 2016, Rol No R-30-2016, Considerando 68 . Este es un punto que ha sido reiteradamente destacado por la doctrina. Véase GuERRA, Felipe, "Los Tribunales Ambientales en la implementación de los derechos indígenas durante la evaluación ambiental de proyectos de inversión en Chile", Revista Justicia Ambiental, 2017, Nº9, p. 31 y Millamán, Sergio, "Consulta Indígena, pueblo mapuche, territorios y evaluación medioambiental", Documento de Trabajo ICSO, $\mathrm{N}^{\circ} 52,2019$, pp. 12 y ss.

56 Tercer Tribunal Ambiental, 17 de noviembre de 2016, Rol No R-30-2016, Considerando $75^{\circ}$.

${ }^{57}$ Tercer Tribunal Ambiental, 17 de noviembre de 2016, Rol No R-30-2016, Considerando $75^{\circ}$.
} 
proporcionó "antecedentes concretos" que acreditaran dichos impactos ${ }^{58}$. Junto a ello, se detiene a examinar el rigor metodológico de los informes que sí había acompañado el reclamante, desestimándolos en base a que "presentan una serie de falencias que imposibilitan su uso como evidencia de afectación directa y significativa a la Comunidad". ${ }^{59}$

Una lógica similar se ha replicado en las últimas sentencias del TTA. En "Piscicultura Lago Balmaceda", por ejemplo, el tribunal confirmó que el "umbral de significancia" que se debía cumplir era aquel del art. 11 de la Ley No19.300 y, ante este estándar, la recurrente no había aportado elementos que permitieran cuestionar la ponderación realizada por el SEA ${ }^{60}$ En razón de ello, desestimó la reclamación. En "Minicentral Las Flores" y "Piscicultura San Joaquín", en cambio, el TTA acoge parcialmente las reclamaciones, pero sin decretar la necesidad de una evaluación del proyecto por EIA, ni ordenar la apertura de un PCI como habían solicitado los reclamantes. ${ }^{61}$ Es importante subrayar que, en estos casos, una lectura de los antecedentes permite observar que las organizaciones y personas indígenas recurrieron a dos estrategias distintas para buscar la invalidación de las respectivas RCAs. En "Minicentral Las Flores", se cuestionó la aprobación del proyecto en base a la existencia de vicios del procedimiento administrativo relacionados con el fraccionamiento y las reuniones del art. 86. En "Piscicultura San Joaquín", se señaló que los modelos técnico-ambientales presentados por el titular no permitían descartar la generación de impactos significativos. Las reclamaciones fueron exitosas en estos puntos. ${ }^{62}$ Sin embargo, debido a que estos mismos defectos en la evaluación y en la información aportada por el titular no permitían concluir sobre la existencia de impactos significativos, y a que los recurrentes no habían aportado antecedentes en ese sentido, las acciones no prosperaron en lo que respecta a la evaluación del proyecto

\footnotetext{
${ }^{58}$ Tercer Tribunal Ambiental, 28 de diciembre de 2016, Rol No R-38-2016, Considerando $36^{\circ}$.

${ }^{59}$ Tercer Tribunal Ambiental, 28 de diciembre de 2016, Rol No R-38-2016, Considerando $37^{\circ}$.

${ }^{60}$ Tercer Tribunal Ambiental, 27 de noviembre de 2019, Rol No R-9-2019, Considerando $64^{\circ}$ a $72^{\circ}$.

${ }^{61}$ Sobre la solicitud de EIA y consulta, en "Minicentral Las Flores" ver: Tercer Tribunal Ambiental, 7 de junio de 2019, Rol N R-78-2018, Considerando $2^{\circ}$. En "Piscicultura San Joaquín", ver: Tercer Tribunal Ambiental, 31 de marzo de 2020, Rol No R-12-2019 (acumuladas R-14-2019 y R-15-2019), Considerandos $43^{\circ}$ y $49^{\circ}$.

${ }^{62}$ En el caso de "Minicentral Las Flores", ver: Tercer Tribunal Ambiental, 7 de junio de 2019, Rol N ${ }^{\circ}$ R-78-2018, Considerandos $31^{\circ}$ y ss.; y considerandos $53^{\circ}$ y ss. En el caso de "Piscicultura San Joaquín", ver: Tercer Tribunal Ambiental, 31 de marzo de 2020, Rol No R-12-2019 (acumuladas R-14-2019 y R-15-2019), Considerandos $53^{\circ}$ a $80^{\circ}$.
} 
por EIA y la apertura de un PCI. ${ }^{63}$ Estos son ejemplos claros de cómo los tribunales del contencioso-administrativo ambiental, han adoptado sin cuestionamiento la tesis de la homologación entre susceptibilidad de afectación directa e impactos significativos.

En lo que se refiere al "efecto de desplazamiento", las consecuencias de la reproducción de este criterio en sede judicial son claras. Piénsese en un caso en que, en base a la información aportada por el Titular, la autoridad ambiental haya decidido que no hay afectación. De acuerdo a lo fallado por el TTA, en sede judicial corresponderá a las organizaciones o familias indígenas reclamantes "justificar (...) la falta de fiabilidad o insuficiencia de esa información, su incorrecta valoración o motivación en la RCA, o suministrar en la reclamación los antecedentes que permitan desvirtuar la conclusión arribada por la Administración". ${ }^{64}$ Dadas las complejidades que significa para las organizaciones indígenas el generar "evidencia de afectación directa y significativa" para desvirtuar el juicio de la autoridad ambiental, no es extraño que vuelquen su atención hacia las dos primeras opciones esbozadas por el tribunal. Así, por una parte, se intentará impugnar la información presentada por el Titular en sus respectivos informes técnicos. Esto implicará entrar a discutir, por ejemplo, si se cumplió con la metodología básica de producción de conocimiento científico para una determinada área, como se vio en el caso de "Central Mediterráneo" o "Piscicultura San Joaquín". Por otra, tratará de identificar vicios del procedimiento administrativo que puedan afectar la motivación de la RCA, como sucedió en "Minicentral Las Flores" y parcialmente en "Central Doña Alicia". A pesar de sus diferencias, ambas estrategias suponen un desplazamiento las discusiones sobre las características de los impactos o la idoneidad de las medidas, por debates de orden metodológico o procedimental.

\section{La forma de cumplimiento de la obligación de consulta}

He explicado cómo la regulación y práctica administrativa-ambiental en materia de consulta comprende este derecho como una "obligación de medio". Por ella, el Estado se obliga a efectuar todos los esfuerzos

\footnotetext{
${ }^{63}$ Ver, respectivamente: Tercer Tribunal Ambiental, 7 de junio de 2019, Rol No R-78-2018, Considerando $82^{\circ}$; y Tercer Tribunal Ambiental, 31 de marzo de 2020, Rol No R-12-2019 (acumuladas R-14-2019 y R-15-2019), Considerando $81^{\circ}$.

${ }^{64}$ Tercer Tribunal Ambiental, 7 de junio de 2019, Rol N R-78-2018, Considerando 82 .
} 
razonables para obtener el consentimiento de las comunidades indígenas sobre -principal, pero no exclusivamente- las medidas para hacerse cargo de los impactos significativos que genere un proyecto sometido a evaluación. Sin embargo, la no obtención de este consentimiento -por ejemplo, porque una comunidad estimó que las medidas no eran idóneas para mitigar, reparar o compensar un efecto adverso- no implica una infracción a este derecho. En consecuencia, el test de cumpliento de la cosulta en el SEIA se limita a enumerar las instancias de diálogo que existieron con la comunidad, con independencia del resultado del proceso. Esto es, no existe un análisis o justificación de por qué, a pesar de la negativa explícita del grupo afectado, las medidas propuestas por el titular serían capaces de hacerse cargo del impacto.

Aun cuando hay escasa jurisprudencia sobre el tema, aquella existente apuntaría -aunque de manera indirecta- a la misma comprensión de la consulta. La primera decisión en donde es apreciable esta lógica, es en el voto concurrente del Ministro Sabando del STA, en "RT Sulfuros". No habiendo otorgado su consentimiento durante el PCI, la Comunidad Indígena Atacameña San Francisco de Chiu-Chiu reclamó judicialmente tanto que sus observaciones PAC no habían sido consideradas, como cuestiones específicas relativas al PCI; entre estas últimas, que no se tomaron en cuenta sus requerimientos sobre el depósito de relaves en el tranque Talabre. Si bien el STA desestimó las alegaciones sobre la consulta por razones formales, el Ministro Sabando difiere de esta apreciación y entra a analizar derechamente los puntos relevados por la comunidad.

El reclamo de la comunidad sobre el tranque Talabre sostenía la invalidez del PCI por no aceptarse la condición dispuesta por ella para otorgar su consentimiento, cual era, que los relaves fuesen depositados en un tranque diverso al actual. El Ministro rechaza dicha alegación. Para ello, simplemente constató que el SEA realizó todas las etapas formales del proceso y apuntó al hecho que el retiro de una comunidad del PCI no le resta validez a este. ${ }^{65}$ Es decir, el Ministro no repara en si, por ejemplo, las medidas eran efectivamente idóneas para hacerse cargo de los impactos asociados al tranque; ni cuáles fueron las razones de la autoridad para desestimar la petición de la Comunidad. De esta manera, replicando la lógica de la "obligación de medio", el examen de legalidad se agota en el 23-29. 
cumplimiento formal por parte de la autoridad de los requisitos procesales.

Una segunda decisión en este sentido se encuentra en la sentencia del TTA en "PE Puelche Sur". Acá, la Comunidad Indígena Mapuche Huilliche Weichan Mapu buscaba la invalidación de la RCA del proyecto porque, entre otras razones, en esta no se había dado respuesta a las observaciones formuladas durante el PCI. En lo central, el TTA también desestima la reclamación por cuestiones formales. Pero, además, afirma que "ni la Ley $\mathrm{N}^{\circ} 19.300$ ni el RSEIA, obliga al SEA a responder o hacerse cargo de los 'comentarios u observaciones' que se realizan en las reuniones de la consulta". ${ }^{66}$ Aun cuando el tribunal estaba enfocado en desvirtuar la posibilidad de utilizar la reclamación del art. $17 \mathrm{~N}^{\mathrm{o}} 6$ dela Ley $\mathrm{N}^{\circ} 20.600$ -relativa a las observaciones ciudadanas- para abordar cuestiones vinculadas a la consulta y, ciertamente, los comentarios de la comunidad no fueron del todo precisos, la aserción es preocupante. En ella se afirma que, respecto del PCI, ni siquiera existiría el deber de la autoridad ambiental de explicar de qué forma una medida como un "Fondo de Desarrollo Comunitario" puede hacerse de "la afectación al valor paisajístico, cultural - ancestral", respecto de una comunidad. Los deberes de la autoridad en la consulta se agotarían, entonces, en la realización de los pasos procesales para alcanzar el consentimiento, sin extenderse al "hacerse cargo" de las inquietudes o argumentos formulados en este proceso por los GHPPI para rechazar el proyecto. ${ }^{67}$

Aunque tal vez no directamente, las decisiones revisadas apuntan a entender a la consulta como una "obligación de medio". Y, con ello, los debates sobre impactos y medidas son desplazados y reemplazados por discusiones sobre la forma en que se realizó la consulta. Corresponde analizar ahora si esta interpretación y aquella sostenida sobre el criterio de procedencia examinadas, resultan jurídicamente plausibles. La respuesta, se puede adelantar, es negativa.

\footnotetext{
${ }^{66}$ Tercer Tribunal Ambiental, 7 de septiembre de 2019, Rol No R-8-2019, Considerando $16^{\circ}$.

${ }^{67}$ Es cierto que en este caso el Titular había acomodado una de las peticiones de la Comunidad relativa a la eliminación de un número de aerogeneradores. Esto, sin embargo, no aminora el hecho que, para el TTA, no habría una obligación jurídica de la autoridad de atender dichos reclamos.
} 


\section{EL “DESPLAZAMIENTO” Y SUS REGLAS DE PRODUCCIÓN}

De acuerdo a lo explicado en las secciones anteriores, la regulación, práctica y jurisprudencia ambiental ha producido y re-producido el "efecto de desplazamiento" a partir de razonamientos hermenéuticos sobre el criterio de procedencia y la naturaleza del derecho a consulta. En el presente apartado, analizaré el fundamento de ambas interpretaciones, para explicar cómo son jurídicamente incorrectos. Comenzaré revisando (1) la interpretación que homologa "susceptibilidad de afectación directa" a "impactos significativos", para luego abordar (2) aquella relativa a la comprensión de la consulta como "obligación de medio".

1. "Susceptibilidad de afectación directa" e "impactos significativos": lo que se pierde en la traducción

El criterio de procedencia de la consulta de acuerdo con art. $6 \mathrm{~N}^{\circ} 1(\mathrm{a})$ del Convenio $\mathrm{N}^{\mathrm{o}} 169$ requiere que las medidas administrativas sean "susceptibles de afectar directamente" a los pueblos indígenas. El art. 11 de la Ley No19.300 habla, en tanto, de "impactos significativos". Según se revisó en la sección (1), en materia ambiental se han equiparado ambos criterios de tal manera que, para hacer procedente una consulta en el SEIA, se requiere que el proyecto genere uno o más de los impactos significativos del art. 11. En este apartado me enfocaré en mostrar cómo esta homologación no es normativamente plausible.

Al respecto, un primer punto a relevar es que ni la Corte Suprema en su momento, ni el SEA con posterioridad, han efectuado un esfuerzo hermenéutico para dar sustento a la equiparación entre ambos conceptos. ${ }^{68}$ Lo más cercano a un intento de este tipo tal vez podría encontrarse en el "Informe final Proceso de Consulta Indígena sobre el Reglamento del SEIA", del año 2012. ${ }^{69}$ Sin embargo, este documento sigue sin explicar

\footnotetext{
${ }^{68}$ Véase SoLís, Osvaldo, "La consulta indígena en el SEIA: criterios para la determinación administrativa de la susceptibilidad de afectación directa", Tesina para optar al grado de Magíster en Derecho con mención en Derecho Administrativo, Pontificia Universidad Católica de Valparaíso, no publicada, 2016, pp. 16-26.

${ }^{69}$ Gobierno de Chile, "Informe final Proceso de Consulta Indígena sobre el Reglamento del SEIA, guías de procedimientos de participación ciudadana y de apoyo para la evaluación de alteraciones significativas sobre Pueblos originarios", 2012, https://sea.gob.cl/informe-final-de-la-consulta-lospueblos-indigenas-del-reglamento-del-seia-ds-ndeg402012, consultado: 17 de noviembre de 2020, pp. 8-12.
} 
jurídicamente la homologación entre ambos supuestos. ${ }^{70}$ Algo similar ocurre con una parte importante de la doctrina que defendió esta línea interpretativa en sus inicios, en el sentido que en sus escritos no se analiza directamente la plausibilidad técnica de la tesis de la homologación. ${ }^{71}$

Dentro de los pocos intentos que ha habido por subsanar este vacío argumentativo, Osvaldo Solís ha postulado ciertos criterios administrativos que en su mirada permitirían armonizar el Convenio No169 y la legislación ambiental. Dentro de estos criterios se encuentra el de la "inmediatez", que es el que interesa para nuestra discusión. Aunque no se define con claridad, su característica principal pareciese estar relacionada con la necesidad de "agregar un elemento de proporcionalidad" a la determinación de la existencia de la susceptibilidad de afectación directa, "de forma de establecer un punto medio entre el no debe consultarse nunca y el debe consultarse en todos los casos". ${ }^{72}$ Según Solís, este criterio se encontraría claramente en los impactos significativos del art. 11 y su reglamentación, y podría inferirse también del Convenio $\mathrm{N}^{\mathrm{o}} 169$, específicamente del hecho que el art. $6 \mathrm{~N}^{\circ} 1$ (a) hable de susceptibilidad de afectación directa. Así, a través de una interpretación "básica, de carácter literal" de esta palabra, el autor entiende que, con el uso del término "directamente", el Convenio Nº 169 "impuso un requisito relativo a la magnitud de la contingencia o posibilidad de afectación, de forma que se elimine toda posibilidad de alteración que no sea una consecuencia inmediata en términos lógicos, temporales y físicos de la medida administrativa a consultar". ${ }^{73}$ Como consecuencia, desde esta perspectiva, el mero emplazamiento de un proyecto en territorio indígena no bastaría para decretar un proceso de consulta. Al contrario, solo en aquellos casos en que exista "una incompatibilidad absoluta entre el uso actual [del territorio] y los efectos, circunstancias o características del proyecto" ${ }^{74} \mathrm{o}$ "que la extensión y la duración de la intervención, justifique que existe una

\footnotetext{
${ }^{70}$ Solís, cit. (n. 68), pp. 23-26.

${ }^{71}$ Ver, por ejemplo, Donoso, Sebastián, "Declaraciones de Impacto Ambiental y Consulta Indígena en el SEIA: Comentario a la tendencia de homologación de los impactos ambientales que exigen un EIA y la susceptibilidad de afectación directa del Convenio 169 OIT", en: Sentencias Destacadas 2013, Libertad y Desarrollo, Santiago, 2013, pp. 78 y 79; y CARrasco, Edesio, "Razonabilidad y proporcionalidad: criterios para la determinación de la consulta indígena en proyectos de inversión en el marco del convenio No 169 de la OIT", Revista Chilena de Derecho, 2013, Vol. 40, No 1, p. 309.

${ }^{72}$ Solís, cit. (n. 68), p. 43. Énfasis original.

${ }^{73}$ Solís, cit. (n. 68), p. 44.

${ }^{74}$ Solís, cit. (n. 68), p. 47. Énfasis agregado.
} 
verdadera afectación", ${ }^{75}$ es que será procedente abrir un procedimiento consultivo.

El problema principal con la tesis de Solís, estimo, es que se basa en una interpretación equivocada del art. $6 \mathrm{~N}^{\mathrm{o}} 1$ (a). Como él mismo señala, su lectura se deriva de "una interpretación básica, de carácter literal" del término "directamente". Pero esta no es la regla hermenéutica legalmente aplicable al Convenio $\mathrm{N}^{\mathrm{o}} 169$. En tanto tratado internacional, sus disposiciones deben ser interpretadas de acuerdo con la "regla general de interpretación" de la Convención de Viena sobre el Derecho de los Tratados (CVDT) (art. 31, CVDT) ${ }^{76}$ Esta regla, en su disposición central, señala que tal interpretación debe ser "de buena fe conforme al sentido corriente que haya de atribuirse a los términos del tratado en el contexto de estos y teniendo en cuenta su objeto y fin" (art. $31 \mathrm{~N}^{\circ} 1$, CVDT).

Siguiendo las prescripciones hermenéuticas de la CVDT, el resultado de una lectura del art. $6 \mathrm{~N}^{\mathrm{o}} 1$ (a) es el opuesto al expresado por Solís: no sería necesaria la existencia de una "afectación verdadera", ni que la incompatibilidad entre los usos del territorio y las características del proyecto fuese "absoluta", para abrir un PCI. Considérese, primero, que una interpretación de "buena fe" obliga a considerar al estándar en su conjunto -i.e., la "susceptibilidad de afectación directa"- y no solo uno de sus términos aisladamente. Teniendo en cuenta lo anterior, un examen del "sentido corriente" de los términos del art. $6 \mathrm{~N}^{\circ} 1$ (a) arroja que "son pueblos interesados aquellos capaces de ser afectados directamente por una medida que se prevea dictar, no aquellos que necesariamente vayan a ser afectados". ${ }^{77} \mathrm{Si}$, a continuación, se ubica esta disposición en el contexto mayor del Convenio $\mathrm{N}^{\circ} 169$, se encuentra que una lectura amplia del criterio de procedencia es sistemáticamente consistente con la norma del art. 7 $\mathrm{N}^{0} 3$ del tratado, según la cual los estudios de impacto social, espiritual, cultural y ambiental deben ser efectuados "en cooperación" con los pueblos

\footnotetext{
${ }^{75}$ Solís, cit. (n. 68), pp. 47 y 48 . Énfasis agregado.

${ }^{76}$ Ver Organización Internacional del TRABajo, “Observación General sobre la obligación de consulta. Convenio sobre pueblos indígenas y tribales, 1989 (núm. 169)", 7 de febrero de 2011, https://www. ilo.org/global/standards/subjects-covered-by-international-labour-standards/indigenous-and-tribalpeoples/WCMS_305844/lang--es/index.htm, consultada: 20 de julio de 2020. Sobre la interpretación según las reglas de la Convención de Viena, véase: Villiger, Mark, Commentary on the 1969 Vienna Convention on the Law of Treaties, Martinus Nijhoff Publishers Leiden, 2009, pp. 345 y ss.

${ }^{77}$ López, Ricardo y Mohr, Tania, "Susceptibilidad de afectación directa en la consulta previa del Convenio 169. Análisis de Normas Previstas y de su trato en la Jurisprudencia. ¿Una cuestión de derecho?", Revista de Derecho (Valdivia), 2014, Vol. XXVII, №1, p. 112. Énfasis original.
} 
interesados. Finalmente, esta interpretación es coherente con el "objeto y fin" del Convenio $\mathrm{N}^{\circ} 169$. En el caso del Convenio $\mathrm{N}^{\circ} 169$, recuérdese, el "objeto y fin" sería doble: la mantención y fortalecimiento de la identidad cultural de los pueblos indígenas; y que estos pueblos asuman el mayor control posible de sus formas de vida. ${ }^{78} \mathrm{El}$ entender que la procedencia de la consulta no requiere de certeza ni magnitud en la afectación se alinea con ambos objetivos. Por una parte, "una mayor apertura y flexibilidad en la constatación de esta susceptibilidad de afectación 'cultural' (...) supone acoger la posibilidad de afectación en la forma y medida que los propios indígenas indican". ${ }^{79}$ Por otra, permite la participación temprana de estos pueblos en el proceso de toma de decisión estatal. En suma, una interpretación correcta lleva a concluir que la referencia a una "susceptibilidad de afectación directa" por parte del art. $6 \mathrm{~N}^{\circ} 1$ (a) significaría, valga la obviedad, que la mera susceptibilidad de afectación directa es suficiente para "gatillar" un proceso de consulta.

Ahora bien, ello no supone que se abra un proceso de consulta ante la sola percepción subjetiva de parte de organizaciones indígenas que un proyecto o actividad podría afectarles. Deben existir ciertos indicios objetivos que, a juicio de la autoridad, hagan plausible la posible afectación. Por supuesto, en línea con señalado anteriormente, este umbral de afectación no requiere certeza sobre la generación del impacto, ni que este sea de una magnitud determinada. Por ejemplo, el emplazamiento del proyecto en tierras indígenas, áreas de desarrollo indígena o en las cercanías de GHPPI ${ }^{80}$, debiese bastar la mayoría de las veces para entender que el proyecto es susceptible de afectar directamente a pueblos indígenas. ${ }^{81}$

Visto lo anterior, es posible concluir que la "susceptibilidad de

\footnotetext{
${ }^{78}$ Ver CABRERA, María, The requirement of consultation with indigenous peoples in the ILO: between normative flexibility and institutional rigidity, Brill Nijhoff, Leiden, 2017, p. 60; y RomвouTs, Sebastiaan, "The Evolution of Indigenous Peoples' Consultation Rights under the ILO and U.N. Regimes", Stanford Journal of International Law, 2017, Vol. 53, No2, p. 183.

${ }^{79}$ FAUNDES, Juan Jorge, "Consulta indígena y centrales de generación hidroeléctrica de menos de 3MW: desregulación riesgosa, a la luz del derecho fundamental a la identidad cultural de los pueblos indígenas", en Bozzo, S.; Remeseiro, R.; Esis, I. (Coords.), Memorias III Congreso Internacional de Regulación y Consumo RIL Editores, Santiago, 2020, p. 382.

${ }^{80}$ En el SEIA, estos son los elementos que dan pie a la obligación de la autoridad ambiental de realizar "reuniones" con los GHPPI. Ver el art. 86 del RSEIA.

${ }^{81}$ Un razonamiento de este tipo, aunque en un caso reglado por el RGC, puede encontrarse en Corte Suprema, 4 de abril de 2016, Rol ํ 36.728-2015. En un sentido similar, véase FAUNDES, cit. (n. 79), pp. 278-282.
} 
afectación directa" responde a una lógica diversa de aquella que estructura los "impactos significativos". El primero de estos criterios opera en razón de la mera posibilidad de impacto, el que finalmente será determinado participativamente con los GHPPI. El segundo, en cambio, siguiendo el principio preventivo que anima al SEIA, ${ }^{82}$ en su mayoría funciona en base a riesgos conocidos o comprobados. ${ }^{83}$ Así, demanda "alteración" (art. 11(f)), "efectos significativos" (art. 11 (b)), "reasentamiento" (art. 11(c)) y "alteración significativa" (art. 11, letras c) y e)). Es cierto que el art. 11(a) habla de "riesgo para la salud de la población", pero este se configura objetivamente cuando se superan los valores establecidos en la normativa ambiental (art. 5, RSEIA). Como se puede apreciar de la jurisprudencia de los tribunales del contencioso-administrativo ambiental revisada en la Sección (III.1), la aplicación de este criterio ha derivado en que se rechace la apertura de un PCI a menos que los GHPPI prueben que el proyecto genera una afectación directa y significativa.

Quizás la única vía plausible de comunicación entre ambos criterios sea la norma del art. 11(d). De acuerdo con esta disposición, se deberá presentar un EIA siempre que el proyecto se localice en o próximo a población protegida susceptible de ser afectada. Acá, como ha notado Álvaro Durán, la significancia se explica por el objeto de protección de la norma, cual es, los pueblos indígenas. ${ }^{84}$ Por ende, la mera probabilidad de que estos pueblos fueran afectados sería suficiente para determinar la existencia de esta circunstancia y decretar un PCI. ${ }^{85}$ Con todo, el amplio margen de discrecionalidad establecido por el RSEIA para determinar cuándo hay "susceptibilidad de afectación" -i.e., la extensión, magnitud o duración de la intervención (art. 8, inc. $8^{\circ}$, RSEIA)- y la interpretación un tanto confusa y restrictiva sobre este artículo por el Instructivo de Consulta Indígena, ${ }^{86}$ hacen difícil que en la práctica esta disposición pueda operar

\footnotetext{
${ }^{82}$ Astorga, Eduardo, Derecho Ambiental Chileno. Parte General, Legal Publishing Thomson Reuters, Santiago, 2015, Cuarta Edición Actualizada, pp. 95-98.

${ }^{83}$ Ver López y MoHr, cit. (n. 77), p. 121.

${ }^{84}$ De hecho, esta fue la interpretación sostenida en un momento por el propio SEA. Véase, DuRÁN, cit. (n. 19), p. 167.

${ }^{85}$ Véase DurÁn, cit. (n. 19) pp. 164-166.

${ }^{86}$ En este documento, la DE del SEA señaló que cuando este literal habla de "susceptibilidad de afectación" se refiere simplemente a "la posibilidad de generar una afectación directa sobre GHPPI, afectación que a su vez consiste en los impactos del artículo 11 letra (c) y (f) de la ley $\mathrm{N}^{\circ} 19.300 "$ ". DE del SEA, Of. Ord. $\mathrm{N}^{\circ} 16111$ del 24 de agosto de 2016, p. 21. Para una crítica de este instructivo, ver Martínez, Pilar, "La jibarización del derecho a la consulta en la reglamentación Administrativa del
} 
como "bisagra" entre ambos estándares.

En suma, la traducción de la "susceptibilidad de afectación directa" en los "impactos significativos" no es normativamente plausible. Básicamente, porque lo que se pierde en esta traducción es la facultad consagrada en la regla del Convenio $\mathrm{N}^{\mathrm{o}} 169$ de que los GHPPI de participen en la determinación de impactos. Y si este argumento es correcto, entonces el "efecto de desplazamiento" de la consulta en el SEIA sería producto, al menos en lo que respecta a este tópico, de una interpretación errónea de las fuentes pertinentes.

\section{Medio, resultado y los derechos sustantivos de los pueblos indígenas}

En las secciones precedentes revisé cómo la autoridad ambiental y los tribunales del contencioso-administrativo ambiental han generado el desplazamiento de las discusiones sustantivas por cuestiones procedimentales, al sostener una comprensión de la naturaleza de la consulta como "obligación de medio". Bajo esa lectura, este derecho se entiende cumplido por parte de la autoridad al asegurar formalmente la participación informada y de buena fe del pueblo indígena, con independencia de si se obtiene o no el consentimiento del pueblo afectado.

En principio, esta comprensión de la consulta no es completamente errónea. Primero, porque efectivamente la consulta supone un proceso participativo de búsqueda del consentimiento. ${ }^{87}$ Segundo, porque salvo aquellos casos en donde excepcionalmente el consentimiento se establece como requisito, ${ }^{88}$ es relativamente pacífico que "las consultas no implican un derecho de veto ni su resultado será necesariamente alcanzar un acuerdo o lograr el consentimiento". ${ }^{89}$ Sin embargo, de ello no se sigue que se trate de una "obligación de medio".

\footnotetext{
Sistema de Evaluación de Impacto Ambiental Chileno", Tesina para optar al grado de Magíster en Derecho con mención en Derecho Administrativo, Pontificia Universidad Católica de Valparaíso, no publicada, 2018.

${ }^{87}$ Yrigoyen, Raquel, "De la tutela indígena a la libre determinación del desarrollo, participación, consulta y consentimiento", El Otro Derecho, 2009, N40, p. 32.

${ }^{88}$ Para un análisis de las diversas causales de consentimiento y su peso normativo de acuerdo a las fuentes del Derecho Internacional Público, ver CARmona, Cristóbal, "Consentimiento Libre, Previo e Informado en el contexto de proyectos extractivos en territorio indígena: ¿Regla general y derecho consuetudinario internacional?", Revista Brasileira de Políticas Públicas, 2019, Vol. 9, No3, pp. 372399.

${ }^{89}$ Organización Internacional del Trabajo, cit. (n. 76).
} 
En sentido estricto, la consulta tiene dos finalidades u objetivos. Junto a aquel de obtener el consentimiento ("consensus-building"), tiene el fin de proteger los derechos sustantivos de los pueblos indígenas ("rightsprotective"). ${ }^{90}$ Así, como expresa el art. $2 \mathrm{~N}^{\circ} 1$ del Convenio $\mathrm{N}^{\circ} 169$, y han subrayado los órganos de supervisión de la OIT, la consulta debe entenderse como parte de una acción coordinada y sistemática por parte del Estado "con miras a proteger los derechos de esos pueblos y a garantizar el respeto de su integridad". ${ }^{91}$ Es, como lo señalaron AnAya y Puig, un medio para la garantizar la observancia de estos derechos, ${ }^{92}$ cuestión que ha sido reconocida explícitamente por órganos jurisdiccionales tan dispares como la Corte Suprema ${ }^{93}$ y la Corte Interamericana de Derechos Humanos. ${ }^{94}$

Una consecuencia de esta doble finalidad de la consulta es que no implica solo obligaciones de medio, sino también de resultado. Como ha dicho ANAYA: "junto con las garantías procedimentales aplicables, e independientemente que se alcance un acuerdo, las consultas deben llevar a la toma de decisiones que sean compatibles con los derechos sustantivos de los pueblos indígenas". ${ }^{95}$ Esta interpretación de la consulta ha sido refrendada explícitamente por la propia OIT. ${ }^{96}$ Esta obligación de resultado de la consulta se traduce en que los derechos sustantivos serán límites para

${ }^{90}$ Anaya, James y Puig, Sergio, "Mitigating State Sovereignty: The Duty to Consult with Indigenous Peoples", University of Toronto Law Journal, 2017, Vol. 67, №4, pp. 448 y 449. Ver también, MezALOPEHANDÍA, Matías, "La jurisprudencia del multiculturalismo en chile: la consulta previa indígena ante tribunales", Revista de Ciencias Sociales, 2016, N69, p. 22.

${ }^{91}$ Organización Internacional del Trabajo, "Informe del Comité encargado de examinar la reclamación en la que se alega el incumplimiento por Brasil del Convenio sobre pueblos indígenas y tribales, 1989 (núm. 169), presentada en virtud del artículo 24 de la Constitución de la OIT por el Sindicato de Ingenieros del Distrito Federal (SENGE/DF)", GB.304/14/7, 17 de marzo de 2009, párr. 43.

${ }^{92}$ Anaya y Puig, cit (n. 90), p. 456.

${ }^{93}$ Ver, por ejemplo, Corte Suprema, 30 de enero de 2017, rol 65.349-2016, Considerando $8^{\circ}$.

${ }^{94}$ Corte Interamericana de Derechos Humanos, Sentencia del 8 de octubre de 2015, Comunidad Garifuna de Punta Piedra y sus miembros vs. Honduras, Serie C No. 288, párr. 215.

${ }^{95}$ AnaYa, James, Los pueblos indigenas en el derecho internacional, Editorial Trotta, Madrid, 2005, p. 237. Es interesante notar que el "Informe final Proceso de Consulta Indígena sobre el Reglamento del SEIA" se cita el fragmento inmediatamente anterior a este de la obra de Anaya, relativo a las garantías procesales de la consulta, omitiéndose precisamente la idea referida a la protección de los derechos sustantivos de los pueblos indígenas. Véase, Gobierno de Chile, cit. (n. 69), pp. 19 y 20.

96 Ver Organización Internacional del Trabajo, Comprender el Convenio sobre pueblos indígenas y tribales, 1989 (núm. 169). Manual para los mandantes tripartitos de la OIT, Oficina Internacional del Trabajo, Ginebra, 2013, p. 17. 
la adopción de una medida por parte del Estado, ${ }^{97}$ obligando a modificarla para acomodar la protección de los derechos e intereses de los pueblos indígenas y a justificarla cuando esto no fuese posible. ${ }^{98}$ Asimismo, en tanto derechos pertenecientes al Derecho Internacional de los Derechos Humanos, su restricción deberá cumplir con los requisitos de necesidad y proporcionalidad en relación con un objetivo válido del Estado. ${ }^{99}$

En el contexto del SEIA, ante un rechazo por parte del GHPPI de las medidas propuestas por el titular, la autoridad ambiental deberá analizar si efectivamente dichas medidas son idóneas para hacerse cargo de los impactos. Si estima que no lo son, el SEA deberá recomendar el rechazo del proyecto (art. 9 bis, Ley $\mathrm{N}^{\circ} 19.300$ ) y, subsecuentemente, la COEVA deberá calificarlo negativamente (art. 16, inc. final, Ley No 19.300). ${ }^{100} \mathrm{Si}$ considera que, no obstante los reparos realizados por el grupo indígena, las medidas propuestas sí permiten hacerse cargo adecuadamente de los impactos significativos del proyecto, entonces deberá justificar pormenorizadamente esta decisión. En este sentido, las obligaciones sustantivas y el principio de buena fe de la consulta encuentran expresión en la necesidad de una justificación normativamente adecuada de la decisión. ${ }^{101}$

Para ilustrar cómo operaría este deber de justificación piénsese, por ejemplo, en un impacto sobre el derecho a la identidad cultural indígena por la intervención o proximidad de una obra del proyecto a un sitio de significación cultural. Para hacerse cargo de dicho efecto, el titular propone una medida de compensación consistente en un Fondo de Desarrollo para que los GHPPI puedan financiar iniciativas de índole cultural. Los GHPPI, durante el PCI, rechazan la idoneidad de la medida argumentando que no es apta para abordar la afectación al patrimonio inmaterial. Pues bien,

\footnotetext{
${ }^{97}$ Errico, Stefania, "Control over Natural resources and Protection of the Environment of Indigenous Territories", en: Hohmann, J.; Weller, M. (Eds.), The UN Declaration on the Rights of Indigenous Peoples. A Commentary, Oxford University Press, Oxford, 2018, p. 441.

${ }^{98}$ Anaya, cit. (n. 95), p. 237.

${ }^{99}$ AnAYa y Puig, cit. (n. 90), p. 461.

${ }^{100}$ Aun cuando es una cuestión controvertida, estimo que no sería posible para la autoridad ambiental, sea al momento de la calificación o en la etapa recursiva administrativa, el modificar unilateralmente o agregar una medida ambiental como condición, pues el objetivo del SEIA es precisamente que esas medidas sean sometidas al escrutinio de los órganos sectoriales competentes y la ciudadanía. Para un argumento en este sentido, ver InsunZA, Ximena, "Punta Alcalde: el riesgo de extender los límites", Anuario Derecho Público UDP, 2014, Universidad Diego Portales, pp. 393-422.

${ }^{101}$ CRAIK, Neil, "Process and Reconciliation: Integrating the Duty to Consult with Environmental Assessment”, Osgoode Hall Law Journal, 2016, Vol. 53, №2, pp. 645 y 646.
} 
para cumplir con las obligaciones sustantivas del derecho a consulta, la autoridad ambiental no solo debiese evaluar los argumentos de los GHPPI sino, además, justificar por qué no es posible mitigar o reparar el impacto y de qué manera la medida puede entenderse "equivalente" al efecto adverso identificado (art. 100, RSEIA). ${ }^{102}$ Los tribunales del contencisoadministrativo ambiental, en tanto, deberán controlar la motivación de la RCA especialmente en este punto.

Por todo lo anterior, la interpretación de la naturaleza de la consulta como "obligación de medio" actualmente sostenida por la práctica y jurisprudencia ambiental, corresponde a una comprensión parcial de este derecho. En consecuencia, el actuar de la COEVA en casos como "Terminal GNL", al no dar la debida consideración a los argumentos manifestados por las organizaciones indígenas durante el PCI, implica una vulneración a las obligaciones derivadas del derecho a consulta y, con ello, al deber de motivación del acto administrativo (arts. 11 inc. $2^{\circ}$ y 41 inc. $4^{\circ}$, Ley No19.880, 2003). Y, si esto es así, entonces el "efecto de desplazamiento" generado a partir de dicha interpretación es arbitrario.

\section{CONCLUSIONES}

En los últimos años, una parte del déficit de la consulta para asegurar la protección de los derechos sustantivos de los pueblos indígenas en el SEIA se explicaría, hasta cierto punto, a partir del llamado "efecto de desplazamiento". Este efecto se refiere a cómo la consulta desplaza las discusiones sobre cuestiones sustantivas por debates de índole procedimental y metodológico. El problema que surge con este fenómeno es que este desplazamiento es siempre temporal y parcial. ${ }^{103}$ Los desacuerdos sustantivos que pudiesen existir entre comunidades indígenas y el Estado sobre un determinado proyecto, por más que se intente disolverlos o desplazarlos en debates formales, volverán a emerger. Y ello, posiblemente, tanto por vías no violentas -acciones judiciales o administrativas en otras instancias- como violentas -acciones directas/policiales para impedir/asegurar la realización del proyecto-.

\footnotetext{
${ }^{102}$ Sobre las compensaciones en el SEIA, ver Hervé, Dominique, Justicia Ambiental y Recursos Naturales, Ediciones Universitarias de Valparaíso, 2015, pp. 341-344.

${ }^{103}$ RodríGuez, cit. (n. 8), p. 63.
} 
En este contexto, el presente artículo ha buscado mostrar cómo este “efecto de desplazamiento" se genera en el SEIA a partir de la utilización por la regulación, la autoridad y la jurisprudencia ambiental, de interpretaciones restrictivas y parciales sobre el criterio de procedencia y la naturaleza del derecho a consulta. Asimismo, se revisó de qué forma estas interpretaciones se basan en lecturas jurídicamente erróneas de las fuentes relevantes. De lo anterior, es posible concluir que la producción y re-producción del desplazamiento a nivel reglamentario y de práctica administrativa y judicial, puede explicarse antes por la existencia de un sesgo infundadamente restrictivo en su interpretación, que por las características de la propia consulta. Y, si esto es así, entonces existe un espacio hermenéutico para que la Administración o los tribunales puedan subvertir, o al menos atenuar, el "efecto de desplazamiento". Esto, estimo, contribuiría a re-legitimar a la consulta como herramienta para la protección de los derechos sustantivos de los pueblos indígenas.

\section{BIBLIOGRAFÍA}

\section{a) Doctrina}

Aguas, Javier y Nahuelpan, Héctor, "Los límites del reconocimiento indígena en Chile neoliberal. La implementación del Convenio 169 de la OIT desde la perspectiva de dirigentes Mapuche Williche", CUHSO, 2019, Vol. 29, $\mathrm{N}^{\circ} 1$, pp. 117-119.

AnAYA, James, Los pueblos indigenas en el derecho internacional, Editorial Trotta, Madrid, 2005.

Anaya, James y Puig, Sergio, "Mitigating state sovereignty: The duty to consult with indigenous peoples", University of Toronto Law Journal, 2017, Vol. 67, Nº, pp. 435-464.

Astorga, Eduardo, Derecho Ambiental Chileno. Parte General, Legal Publishing Thomson Reuters, Santiago, 2015, Cuarta Edición Actualizada.

BARRía, Jessica, "La consulta indígena en la institucionalidad ambiental de Chile: Consecuencias para la minería y las comunidades indígenas Collas de la Región de Atacama", Investigaciones Geográficas, 2019, №57, 57, pp. 76-93.

Bermúdez, Jorge, Fundamentos de Derecho Ambiental, Ediciones Universidad de Valparaíso, Santiago, 2015, 2da. Edición.

CABRERA, María, The requirement of consultation with indigenous peoples in the ILO: between normative flexibility and institutional rigidity, Brill Nijhoff, Leiden, 2017. 
Carmona, Cristóbal, "Consentimiento Libre, Previo e Informado en el contexto de proyectos extractivos en territorio indígena: ¿Regla general y derecho consuetudinario internacional?", Revista Brasileira de Políticas Públicas, 2019, Vol. 9, N33, pp. 372-399.

CARmona, Cristóbal, “¿La identidad cultural como límite de la Consulta Indígena en el SEIA? Notas para una subversión de la comprensión "procedimental" de la consulta", en: FAundes, J.J. y RAmírez, S. (Eds.), Derecho fundamental a la identidad cultural: Abordajes plurales desde América Latina, RIL editores/ Universidad Autónoma de Chile, Santiago, 2020, pp. 343-359.

CARrasco, Edesio, "Razonabilidad y proporcionalidad: criterios para la determinación de la consulta indígena en proyectos de inversión en el marco del convenio No 169 de la OIT", Revista Chilena de Derecho, Vol. 40, N¹: pp. 299314.

Carrasco, Edesio, "De Trillium a Central Los Cóndores: continuidad y cambio del recurso de protección ambiental en veinte años de jurisprudencia”, Justicia Ambiental, 2017, N9, pp. 275-298.

CRAIK, Neil, "Process and Reconciliation: Integrating the Duty to Consult with Environmental Assessment”, Osgoode Hall Law Journal, 2016, Vol. 53, N², pp. 632-680.

Donoso, Sebastián, "Declaraciones de Impacto Ambiental y Consulta Indígena en el SEIA: Comentario a la tendencia de homologación de los impactos ambientales que exigen un EIA y la susceptibilidad de afectación directa del Convenio 169 OIT", en: Sentencias Destacadas 2013, Libertad y Desarrollo, Santiago, 2013, pp. 57-83.

Donoso, Sebastián (2014): “Empresas y comunidades indígenas: el nuevo escenario que plantea el Convenio 169 de la OIT", Temas de la agenda Pública, Vol. 9, No73: pp. 3-20.

DurÁn, Álvaro, "La Susceptibilidad de Afectación Directa a los Pueblos Indígenas como requisito de procedencia de la consulta a los pueblos indígenas en el Sistema de Evaluación de Impacto Ambiental", Revista de Derecho (Universidad Finis Terrae), 2017 Año V, No2, pp. 154-160.

Egaña, Rodrigo, "Las Políticas Públicas en tiempos de crisis", Revista del CLAD Reforma y Democracia, 2009, N49.

ERrico, Stefania, "Control over Natural resources and Protection of the Environment of Indigenous Territories”, en: Hohmann, J. y Weller, M. (Eds.), The UN Declaration on the Rights of Indigenous Peoples. A Commentary, Oxford University Press, Oxford, 2018, pp. 425-457.

FAundes, Juan Jorge, "Consulta indígena y centrales de generación hidroeléctrica de menos de 3MW: desregulación riesgosa, a la luz del derecho fundamental a la identidad cultural de los pueblos indígenas", en Bozzo, S.; Remeseiro, R.; Esis, I. (Coords.), Memorias III Congreso Internacional de 
Regulación y Consumo RIL Editores, Santiago, 2020, pp. 359-398.

Fuentes, Claudio, "Evaluación de impacto ambiental en Chile: Análisis de tendencias 1992-2017", Documento de Trabajo ICSO - N 59, 2019, https:// labconstitucional.udp.c1/documentos/evaluacion-de-impacto-ambiental-en-chileanalisis-de-tendencias-1992-2017/, consultada: 12 de julio de 2020.

Gobierno de Chile, "Informe final Proceso de Consulta Indígena sobre el Reglamento del SEIA, guías de procedimientos de participación ciudadana y de apoyo para la evaluación de alteraciones significativas sobre Pueblos originarios", 2012, https://sea.gob.cl/informe-final-de-la-consulta-los-pueblos-indigenas-delreglamento-del-seia-ds-ndeg402012, consultada: 19 de noviembre de 2020

Guerra, Felipe, “Los Tribunales Ambientales en la implementación de los derechos indígenas durante la evaluación ambiental de proyectos de inversión en Chile", Revista Justicia Ambiental, 2017, N9, pp. 19-38.

Hervé, Dominique, Justicia Ambiental y Recursos Naturales, Ediciones Universitarias de Valparaíso, Santiago, 2015.

Hervé, Dominique y Bascur, Débora, "La Protección de los Derechos de las Comunidades Indígenas en el Sistema de Evaluación de Impacto Ambiental por Parte de los Tribunales Ambientales: ¿Avance y/o Retroceso?”, Justicia Ambiental, 2019, N 11, pp. 197-232.

InsunZA, Ximena, "Punta Alcalde: el riesgo de extender los límites", en: Couso, J. (ed.), Anuario de Derecho Público 2014, Ediciones Universidad Diego Portales, Santiago, 2014, pp. 393-422.

LARSEN, Peter, "Contextualising ratification and implementation: a critical appraisal of ILO Convention 169 from a social justice perspective”, The International Journal of Human Rights, 2020, Vol. 24, N²-3, pp. 94-111.

López, Ricardo y MoHr, Tania, "Susceptibilidad de afectación directa en la consulta previa del Convenio 169. Análisis de Normas Previstas y de su trato en la Jurisprudencia. ¿Una cuestión de derecho?”, Revista de Derecho (Valdivia), 2014, Vol. XXVII, N¹, pp. 105-126.

MARTínez, Pilar, "Lajibarización del derecho a la consulta en la reglamentación Administrativa del Sistema de Evaluación de Impacto Ambiental Chileno", Tesina para optar al grado de Magíster en Derecho con mención en Derecho Administrativo, Pontificia Universidad Católica de Valparaíso, no publicada, 2018.

Meza-Lopehandía, Matías, "La jurisprudencia del multiculturalismo en chile: la consulta previa indígena ante tribunales", Revista de Ciencias Sociales, 2016, N69, pp. 13-52.

Millaleo, Salvador, “Gobernar Consultado? Análisis comparativo respecto a los problemas en relación a las bases y objetos de la consulta indígena (Convenio 169) de los reglamentos aprobados en Chile", en ¿Chile indígena? Desafíos y oportunidades para un nuevo trato, Fundación Chile, Santiago, 2014, pp. 52-102.

Millamán, Sergio, "Consulta Indígena, pueblo mapuche, territorios y 
evaluación medioambiental", Documento de Trabajo ICSO, N 52, 2019, pp. 2-18.

Organización Internacional del Trabajo, "Informe del Comité encargado de examinar la reclamación en la que se alega el incumplimiento por Brasil del Convenio sobre pueblos indígenas y tribales, 1989 (núm. 169), presentada en virtud del artículo 24 de la Constitución de la OIT por el Sindicato de Ingenieros del Distrito Federal (SENGE/DF)", GB.304/14/7, 17 de marzo de 2009.

Organización Internacional del Trabajo, "Observación General sobre la obligación de consulta. Convenio sobre pueblos indígenas y tribales, 1989 (núm. 169)", 7 de febrero de 2011, https://www.ilo.org/global/standards/subjects-coveredby-international-labour-standards/indigenous-and-tribal-peoples/WCMS_305844/ lang--es/index.htm, consultada: 20 de julio de 2020.

Organización Internacional del Trabajo, Comprender el Convenio sobre pueblos indígenas y tribales, 1989 (núm. 169). Manual para los mandantes tripartitos de la OIT, Oficina Internacional de Trabajo, Ginebra, 2013.

Quilaleo, Fernando, "La implementación del Convenio 169 de la OIT en Chile: La paradoja de los derechos indígenas", Anuario de Derechos Humanos (Universidad de Chile), 2018, N¹4, pp. 141-153.

Rawls, John, Teoría de la Justicia, FCE, México, 1990.

Rodríguez, César, Etnicidad.gov. Los recursos naturales, pueblos indígenas y el derecho a consulta previa en los campos sociales minados, Dejusticia, Bogotá, 2012.

Rombouts, Sebastiaan, Having a Say. Indigenous Peoples, International Law and Free, Prior and Informed Consent, Wolf Legal Publishers, Nymegen, 2014.

Rombouts, Sebastiaan, “The Evolution of Indigenous Peoples' Consultation Rights under the ILO and U.N. Regimes", Stanford Journal of International Law, 2017, Vol. 53, N 2, pp. 169-224.

Solís, Osvaldo, "La consulta indígena en el SEIA: criterios para la determinación administrativa de la susceptibilidad de afectación directa", Tesina para optar al grado de Magíster en Derecho con mención en Derecho Administrativo, Pontificia Universidad Católica de Valparaíso, no publicada, 2016

VILLIGER, Mark, Commentary on the 1969 Vienna Convention on the Law of Treaties, Martinus Nijhoff Publishers Leiden, 2009.

YRIGOYEN, Raquel, "De la tutela indígena a la libre determinación del desarrollo, participación, consulta y consentimiento", El Otro Derecho, 2009, №40, pp. 12-53.

\section{b) Jurisprudencia}

Segundo Tribunal Ambiental, 1 de diciembre de 2015, rol No R-54-2014. Segundo Tribunal Ambiental, 16 de agosto de 2018, Rol No R-158-2017. Tercer Tribunal Ambiental, 17 de noviembre de 2016, Rol No R-30-2016. Tercer Tribunal Ambiental, 28 de diciembre de 2016, Rol No R-38-2016. 
Tercer Tribunal Ambiental, 7 de junio de 2019, Rol No R-78-2018.

Tercer Tribunal Ambiental, 7 de septiembre de 2019, Rol No R-8-2019.

Tercer Tribunal Ambiental, 27 de noviembre de 2019, Rol No R-9-2019.

Tercer Tribunal Ambiental, 31 de marzo de 2020, Rol N ${ }^{\circ}$ R-12-2019 (acumuladas R-14-2019 y R-15-2019)

Corte de Apelaciones de Iquique, 18 de febrero de 2014, Rol No 27-2014.

Corte de Apelaciones de Santiago, 20 de octubre de 2014, Rol No 19.8392014.

Corte Suprema, 4 de abril de 2016, Rol No 36.728-2015.

Corte Suprema, 19 de mayo de 2016, Rol No 817-2016.

Corte Suprema, 30 de enero de 2017, Rol No 65.349-2016.

Corte Suprema, 16 de marzo de 2017, Rol No 55.203-2016.

Corte Suprema, 29 de diciembre de 2017, Rol No 100.805-2016.

Corte Suprema, 28 de junio de 2018, Rol No 3.971-2017.

Corte Suprema, 15 de mayo de 2019, Rol No 197-2019.

Corte Suprema, 16 de junio de 2020, Rol No 28.195-2018.

Contraloría General de la República, 12 de noviembre de 2014, Dictamen $\mathrm{N}^{\circ} 88.248$.

Contraloría General de la República, 24 de abril de 2015, Dictamen $N^{\circ}$ 32.996 .

Corte Interamericana de Derechos Humanos, Sentencia del 8 de octubre de 2015, Comunidad Garifuna de Punta Piedra y sus miembros vs. Honduras, Serie C No. 288.

\section{c) Normas}

Ley N¹9.300, Ley sobre Bases Generales del Medio Ambiente, 1994.

Ley $N^{\circ} 19.880$, Establece Bases de los Procedimientos Administrativos, 2003.

Ley No20.600, Crea los Tribunales Ambientales, 2012

Decreto No381, Promulga la Convención de Viena sobre el Derecho de los Tratados y su Anexo, 1981.

Decreto No236, Promulga el Convenio $\mathrm{N}^{\circ} 169$ sobre pueblos indígenas y tribales en países independientes de la Organización Internacional del Trabajo, 2008.

Decreto Supremo No40, Aprueba reglamento del Sistema de Evaluación de Impacto Ambiental, 2012.

Decreto Supremo Nº6, Aprueba reglamento que regula el procedimiento de consulta indígena en virtud del artículo $6 \mathrm{~N}^{\mathrm{o}} 1$ letra a) y $\mathrm{N}^{\mathrm{o}} 2$ del Convenio $\mathrm{N}^{\mathrm{o}} 169$ de la Organización Internacional del Trabajo, 2013. 